\section{Original Research}

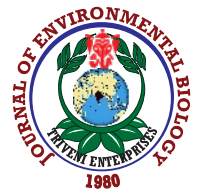

DOI : http://doi.org/10.22438/jeb/41/2(SI)/JEB-24
Journal Home page : www.jeb.co.in $\star$ E-mail : editor@jeb.co.in Journal of Environmental Biology

p-ISSN: 0254-8704 e-ISSN: 2394-0379 CODEN: JEBIDP

\title{
Reflection of environmental-based agricultural land protection program (Çatak) on farmer's implementation
}

\author{
H.E. Salalı ${ }^{1 *}$, E. Atış', Y. Akyüz', V. Ceyhan'², H. Türkten², Ç. Yıldırım², M. Hasdemir ${ }^{3}$ and F.U. Güngör ${ }^{3}$ \\ 'Department of Agricultural Economics, Faculty of Agriculture, Ege University, Izmir-35100 Turkey \\ ${ }^{2}$ Department of Agricultural Economics, Faculty of Agriculture, Ondokuz Mayıs University, Samsun, 55139, Turkey \\ ${ }^{3}$ Turkish Republic Ministry of Agriculture and Forestry, Ankara, 06560, Turkey \\ *Corresponding Author Email : ecesalali@gmail.com
}

Paper received: 19.04 .2019

Revised received: 02.09 .2019

Accepted: 03.01 .2020

\section{Abstract}

Aim: Applied policies towards production increase in the agricultural sector have a significant influence on the environment. The present study aimed to evaluate reflection on farmer's implementations before and after the application of ÇATAK (environment based agricultural land protection program), a prominent agro-environment policy for Turkish agriculture.

\section{Succeeded Implementations of Categories}

Methodology: Face to face interviews were made with the farmers under ÇATAK covering five different provinces of Turkey.

Results: The production techniques like certified organic farming, controlled use of pests and fertilizers have increased significantly after the policy. These results indicate that ÇATAK program is reflected in the farmer's practices and policy has proved effectively in the mentioned implementations.

Interpretation: The policy has been effective in Minimum Tillage which is the implementation of $1^{\text {st }}$ category of ÇATAK program, consisting of 3 categories. It was also concluded that Stone Removing, Drainage, Gypsum Implementation, Use of Farm Manure and Drip Irrigation were effective after ÇATAK program.

Key words: Agro-environment, ÇATAK, Farmer practices, Policymakers

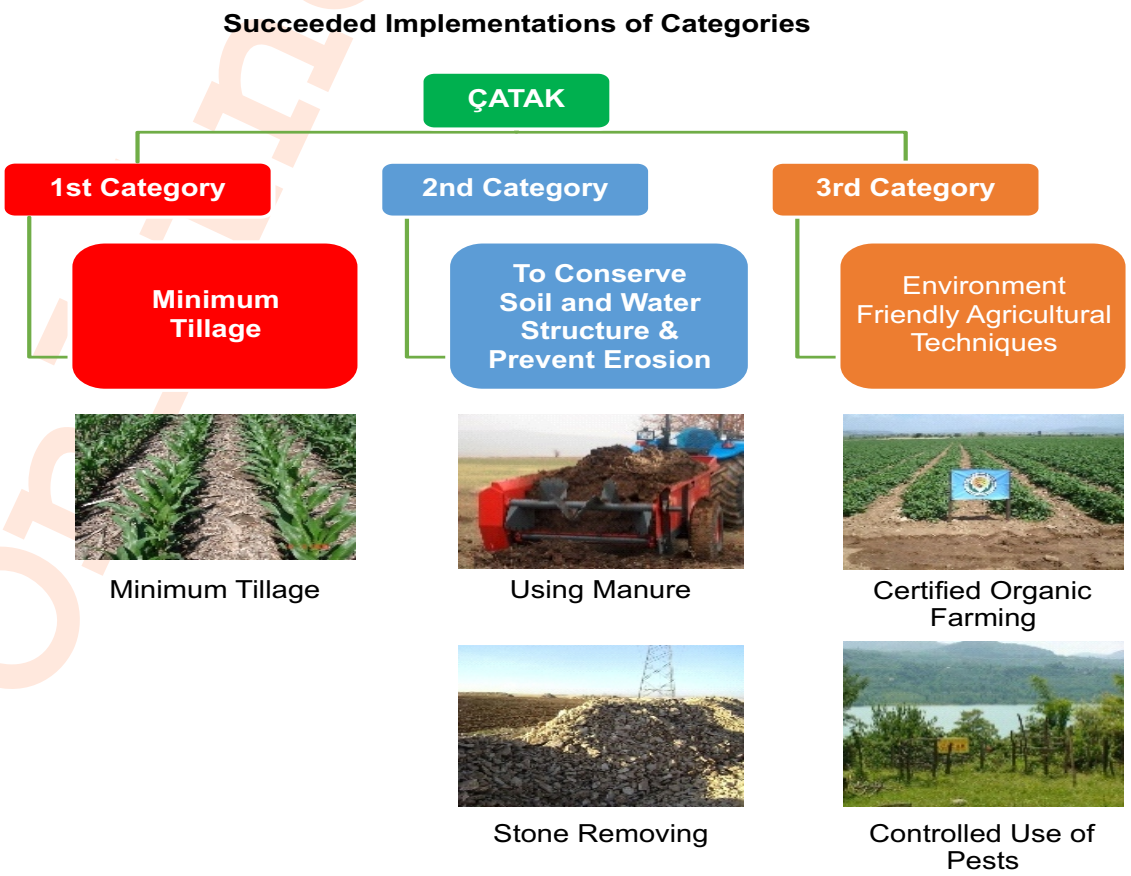

How to cite : Salalı, H.E., E. Atış, Y. Akyüz, V. Ceyhan, H. Türkten, Ç. Yıldııı, M. Hasdemir and F.U. Güngör: Reflection of environmental-based agricultural land protection program (Çatak) on farmer's implementation. J. Environ. Biol., 41, 439-444 (2020). 


\section{Introduction}

Environment is the main factor in agricultural production, and cropping patterns are in accordance with the environmental regulations. Farmers simply aim to increase the yield for good economical gain, therefore, they do not take into account the negative effects on the environment due to the use of chemical fertilizers, pesticides, growth regulators and over-irrigation, as production inputs directly harm the environment (Rathiya et al., 2010; Pandey et al., 2006; Verma and Sagar, 2019). The damage occurs in the form of soil, water, and air pollution. Besides, loss of biodiversity can lead to environmental degradation like soil erosion (Bargali et al., 1992 and 1993; Joshi et al., 1997). Increased agricultural mechanization also deteriorates the soil structure (Parihaar et al., 2014; Bargali et al., 2019). Understanding the importance of agro-environmental issues at the global level has pushed many countries, especially the European Union, to contribute towards the development of policies in this field and to increase funds for agro-environmental policies.

Different implementations will be evaluated here in the scope of agro-environmental policies in Turkey. ÇATAK (Environmental Based Land Protection Program) is the most important and comprehensive program. It has been included for the first time in 2006-2010 Agricultural Strategy document prepared by the Ministry of Agriculture and Rural Affairs in 2004 to reduce the negative effects of agricultural practices on the environment. As part of this program, payments are made for 3 years for the specified applications in 3 different categories in the fields to be supported. Within the framework of the decision of the Council of Ministers dated 27/10/2008, numbered 2008/14268, and published in the Official Gazette dated 14/11/2008 numbered $27054,1^{\text {st }}$ and $3^{\text {rd }}$ categories of ÇATAK previously applied in 3 categories have been consolidated and applied in 2 categories starting from 2009. From 2011, minimum tillage was made a separate category and application realized in the following categories.

According to the notification published in 2016, numbered 29670, the categories (Republic of Turkey Official Gazette, 2016) are: $1^{\text {st }}$ Category: Minimum tillage for the field where annual plants are produced: $2^{\text {nd }}$ Category: In order to conserve soil and water structure and prevent erosion; such as the setting, stone removing, drainage, gypsum implementation, mulching, using farm manure, green manure, preventing overgrazing, covering the field with perennial legumes except for perennial Poaceae or Trifolium, at least two applications be made every year from these measures or to leave the field free with at least one of these measures; $3^{\text {rd }}$ Category: To apply in accordance with at least two or more techniques of environment-friendly agricultural techniques and cultural practices; Use of appropriate pressure irrigation systems to reduce water usage to a minimum; Use of controlled chemicals and fertilizers in an environmentally conscious way; Organic agriculture or good agricultural practices.

Agriculture, environment, and policies lie in a nested, overlapping and interacting position. Nested boundaries of these three can pose a problem for policymakers. Integration of environmental targets within the agricultural sector is seen as possible with appropriate policies. Therefore, this study is important in terms of showing the situation of implementation of agro-environment program.

The subject of policy evaluation is vital for agroenvironmental applications. Governments of different countries are aware of the importance of monitoring and evaluating agricultural environmental policies. In particular (European Union) member countries are obliged to monitor and evaluate the environmental, agricultural and socio-economic impacts of agroenvironment programs (Article 16, EC Regulation No. 746/96; Mauchline et al., 2012). However, there is little consensus on how to successfully monitor and verify the benefits of these programs. No consensus methods are known to monitor the environmental consequences of changing agricultural practices or benefits of agro-environmental policy measures. In many cases the selected goals are difficult to verify and policymakers do not set quantifiable targets, so the action plans are not specified. Nevertheless, they can all contribute to the development of environmental policy and integration of environmental issues in sectoral policies (EEA, 2006).

One of the major difficulties on the evaluation of agroenvironmental measures is the availability of data. Even if there are deficiencies, it is stated that survey data can be used for the evaluation (Höjgård and Rabinowicz, 2012). In another study (Boz, 2018), focus group interviews have been conducted to address common issues related to program enrollment and sustainable use of farm resources. In some studies Huh (2000) and Kim et al. (2003) the performance of agro-environmental programs has been evaluated with the results of surveys conducted with farmers participating in these programs. Oladele and Ward (2017) carried out a study on the livelihood capital of beneficiaries of the capital, as affected by Micro-Agricultural Financial Institutions by Wilcoxon Signed Rank test. In another study, Wilcoxon signed-rank tests were used by Didarali and Gambiza (2019) to test differences in mean income and the size of cultivated areas between South Africa and Zimbabwe. They compared the average number of crop varieties grown before and after permaculture.

This study was carried with the objective to determine if there are any changes from the point of view of farmer's 
implementations after ÇATAK. We intended to compare the implementations before and after ÇATAK, based on farmer's practices. The study was carried out in five different regions and provinces of Turkey, and the reflections of the practices were analyzed at farmer's level. The study is expected to guide the policy-makers in terms of determination, implementation, and adoption of agro-environmental policies to be implemented.

\section{Materials and Methods}

The question to be answered was " $\mathrm{C}$ f there has been any change in implementation of farmers after ÇATAK (Environmental Based Land Protection Program). The main material was pooled up from the questionnaires taken from 329 farmers and the implementations were analyzed by Wilcoxon Signed Rank Test designed for the repeated measures, where the farmers were questioned before and after the program.

The most important data group of the study was obtained from the surveys conducted with farmers in selected provinces, where ÇATAK was applied. For this purpose, Adana, Ankara, İmir, Konya and Samsun provinces were included in the study. In this way, a province from each region where the ÇATAK program was implemented in 2013 and before was included in the study. Since there are different ÇATAK categories in the provinces, the selection of these provinces has been effective for the subject. The study should include a certain number of farmers in each of the three categories. In determining the target group, it is important to know the farmer is at which stage of application. For this reason, the farmers at $2^{\text {nd }}$ or $3^{\text {rd }}$ year of ÇATAK application were included in the survey.

The sample size was designed following the proportional sampling procedure outlined by Newbold (1995), with a 95\% confidence interval and $5 \%$ margin of error. The sample was drawn proportionate to population size in 5 provinces. Data were obtained from 329 farmers through face-to-face interviews during March-April 2015. Some implementations pointed out by the Ministry of Agriculture and Forestry were utilized to determine if the policy was efficient at farmer's level. The practices used before and after the ÇATAK program were analyzed by comparing implementations and outcomes before and after the program. Each practice was measured by five-point like RT scale responses ranging from (1) never to (5) always. Wilcoxon Signed Rank Test is designed for using repeated measures where the farmers are questioned before and after the program. Wilcoxon Test is designed to evaluate the difference between two treatments, using the data from repeated-measurements. A repeated-measure study involves only one sample, with each individual in the sample being measured twice. The difference between the two measurements for each individual is recorded as the score for that individual. In Wilcoxon Test, differences should rank from smallest to largest in terms of their absolute magnitude, irrespective of sign or direction (Gravetter and Wallnau, 2015).
Table 1 : Distribution of producers in the scope of the study by provinces and districts

\begin{tabular}{lc}
\hline Province / District & Number of farmers within ÇATAK Program \\
\hline ADANA & \\
Karaisali & 32 \\
ANKARA & 13 \\
Kazan & 5 \\
Sereflikochisar & \\
IZMIR & 16 \\
Bayindir & 7 \\
Menderes & 27 \\
Menemen & 12 \\
Torbali & \\
KONYA & 25 \\
Altinekin & 31 \\
Kadinhani & 40 \\
Sarayönü & \\
SAMSUN & 121 \\
Carsamba & 329 \\
TOTAL &
\end{tabular}

\section{Results and Discussion}

The study was conducted in 11 districts and 57 villages covering 5 provinces. In the scope of ÇATAK program, semiquestionnaires/interviews were used involving 329 farmers (Table 1). Surveys were completed during March-April 2015, following face-to-face semi-interviews (Parihaar et al., 2014).

The results of the demographic characteristics of farmers were followed as; the average age of farmers should be approximately 53 and their agricultural experience 28 years. Time spent on the land should be nearly 170 days in the year. The number of family members working should be approximately 5 and number of family members from family working on agriculture nearly 3 (Table 2 ).

Table 2 shows the implementations for the categories examined in the study area, before and after ÇATAK program. Wilcoxon Signed Rank Test revealed a statistically significant difference between most implementations, except "preventing overgrazing" as shown in Table 3.

The results indicate that in $1^{\text {st }}$ category "minimum tillage" had significantly increased after ÇATAK, followed by $2^{\text {nd }}$ category including "stone removing", "drainage", "gypsum implementation" and "using farm manure", which too increased significantly. On the other hand, "rotation cropping system" and "surface irrigation" decreased significantly, as expected in the study. Besides, the "polyculture" and "drip irrigation" increased intermediately.

In $3^{\text {rd }}$ category, it was seen that "certified organic farming", "controlled use of pests" and "controlled use of fertilizers" had significantly increased. In the light of these results, it can be said 
Table 2 : Demographic characteristics of farmers within ÇATAK Program

\begin{tabular}{lllllll}
\hline & Adana & Ankara & Izmir & Konya & Samsun & General \\
\hline Age of Farmer(Years) & 51.7 & 60.6 & 52.6 & 49.0 & 54.6 & 52.6 \\
Agricultural Experience (Years) & 29.7 & 31.2 & 26.0 & 22.7 & 32.4 & 28.1 \\
Duration of Working (Days) & 102.7 & 279.7 & 262.9 & 194.6 & 103.2 & 169.5 \\
Number of Family Members & 5.2 & 3.7 & 4.0 & 5.5 & 5.2 & 5.0 \\
Number of Family Members From Family Working in Agriculture & 2.4 & 2.5 & 2.0 & 2.3 & 3.3 & 2.6 \\
\hline
\end{tabular}

Table 3 : State of implementations before and after ÇATAK

\begin{tabular}{|c|c|c|c|c|}
\hline & \multicolumn{2}{|c|}{ Mean** } & \multirow[t]{2}{*}{$Z^{b}$} & \multirow[t]{2}{*}{ Sig. } \\
\hline & Before & After & & \\
\hline \multicolumn{5}{|l|}{ 1st Category } \\
\hline Minimum Tillage & $1.489(0.934)^{*}$ & $2.234(1.694)^{*}$ & -72.991 & $0.000^{+}$ \\
\hline \multicolumn{5}{|l|}{ 2nd Category } \\
\hline Setting & $1.073(0.534)^{\star}$ & $1.081(0.563)^{*}$ & -5.554 & $0.000^{+}$ \\
\hline Screening & $1.010(0.147)^{*}$ & $1.130(0.628)^{*}$ & -26.758 & $0.000^{+}$ \\
\hline Stone Removing & $1.818(1.338)^{*}$ & $2.467(1.738)^{*}$ & -73.816 & $0.000^{+}$ \\
\hline Drainage & $1.409(1.190)^{*}$ & $2.130(1.800)^{*}$ & -70.909 & $0.000^{+}$ \\
\hline Gypsum Implementation & $1.191(0.660)^{*}$ & $1.554(1.382)^{*}$ & -48.459 & $0.000^{+}$ \\
\hline Mulching & $1.000(0.000)^{*}$ & $1.046(0.423)^{*}$ & -17.321 & $0.000^{+}$ \\
\hline Using Farm Manure & $2.270(1.620)^{*}$ & $3.168(1.840)^{*}$ & -78.823 & $0.000^{+}$ \\
\hline Green Manure & $1.524(1.167)^{*}$ & $1.651(1.327)^{*}$ & -34.612 & $0.000^{+}$ \\
\hline Preventing Overgrazing & $1.269(0.980)^{*}$ & $1.247(0.944)^{*}$ & .000 & 1.000 \\
\hline Rotation Cropping System & $3.820(1.589)^{*}$ & $3.633(1.744)^{*}$ & -5.372 & $0.000^{+}$ \\
\hline Polyculture & $2.678(1.800)^{*}$ & $2.708(1.847)^{*}$ & -35.222 & $0.000^{+}$ \\
\hline Surface Irrigation & $2.557(1.910)^{*}$ & $2.048(1.711)^{*}$ & -52.319 & $0.000^{+}$ \\
\hline Pond Irrigation & $1.179(0.754)^{*}$ & $1.080(0.460)^{*}$ & -23.516 & $0.000^{+}$ \\
\hline Furrow Irrigation & $1.648(1.411)^{*}$ & $1.635(1.439)^{*}$ & -2.108 & $0.035^{++}$ \\
\hline Sprinkler Irrigation & $2.057(1.741)^{*}$ & $2.173(1.810)^{*}$ & -11.148 & $0.000^{+}$ \\
\hline Drip Irrigation & $1.155(0.708)^{*}$ & $1.780(1.569)^{*}$ & -63.966 & $0.000^{+}$ \\
\hline Fallow & $24.573(86.937)^{*}$ & $23.939(87.782)^{*}$ & -52.116 & $0.000^{+}$ \\
\hline \multicolumn{5}{|l|}{ 3rd Category } \\
\hline Uncertified Organic Farming & $1.668(1.488)^{*}$ & $1.272(1.006)^{*}$ & -51.517 & $0.000^{+}$ \\
\hline CertifiedOrganic Farming & $1.196(0.863)^{*}$ & $1.540(1.367)^{\star}$ & -52.707 & $0.000^{+}$ \\
\hline Good Agricultural Practices & $1.046(0.353)^{*}$ & $1.185(0.826)^{*}$ & -29.565 & $0.000^{+}$ \\
\hline Controlled Use of Pests & $2.385(1.726)^{*}$ & $2.768(1.881)^{*}$ & -59.602 & $0.000^{+}$ \\
\hline Controlled Use of Fertilizers & $2.501(1.762)^{*}$ & $2.970(1.923)^{*}$ & -73.377 & $0.000^{+}$ \\
\hline
\end{tabular}

*Standard deviation (SD);**1: Never, 2: Rarely, 3: Sometimes, 4: Often, 5: Always; 'Significant for Wilcoxon Signed Rank Test,p<0.01; 'Significant for Wilcoxon Signed Rank Test, $p<0.05 ;{ }^{b}$ Null hypothesis was rejected under Wilcoxon Signed Rank Test for $p<0.01$ (Based on negative ranks)

that these farmers are more sensitive to the environment. Olhan et al. (2010) too stated that farmers benefiting from ÇATAK were more sensitive towards the environment compared to other farmers.

Today agriculture is fundamental for the existence and welfare of the global population. For long-run sustainability of the agricultural systems, issues of technological change, management of soil productivity, machinery, fertilizers, and irrigation are much more important. Almost all industrialized countries have pursued policies and regulations designed to support their farmers. There is an increasing concern about natural and environmental resources at public level where the modern agriculture stands currently. Some implementations such as conservation of water and soil resources through drainage, control of pesticides and use of fertilizers, preserving genetic diversity by reducing monoculture are very important and major priorities for farmers. Adopting policy programs such as ÇATAK and implementations like minimum soil processing, mulching and green manure are very important for sustainable agricultural production. According to Boz (2016), the selected sustainable agricultural practices cover adoption of sustainable agricultural 
practices. Chi-square tests have shown that adoption of ÇATAK program was associated with 2 significant variables, i.e., growing forage legumes and use of animal manure. The results of before and after implementations can give the policymakers a chance for developing an effective instrument for the farmers. Farmers have taken advantage of the "Environmentally Based Agricultural Land Protection Program" through efforts undertaken by some implementations such as minimum tillage, setting, stone removal, drainage, gypsum implementation and farm manure usage under ÇATAK program. This program has been engaged in long-run agro-environmental policy planning process which focuses on agricultural practices that decrease the environmental pressure.

The outcome of this study has shown that farmers strongly support the constraints imposed by these policies. Only preventing overgrazing is not as expected. Some of the causes of overgrazing are having too many animals for the grazing space, drought, not utilizing the feeding area of the livestock properly and high cost of livestock feed. When considering the implementation period and the causes, it is seen that this is a long lasting implementation. Öz and Boz (2014) studied the variables which influence the adoption of CATAK program. They found that the success of this program also depends on suggestions such as; facilitating the use of credit for various agricultural investments for farmers and increasing agricultural training and extension services. As the measures to be determined in the relevant area are completely related to environmental problem of that region, ÇATAK is, therefore, an important program. The economic and efficiency analyses by Yıldırım et al. (2018) shows that there is need for sufficiency level of subsidies for environmental protection. We found out that the subsidy level was satisfactory in our research area. The results on opportunity cost of the conversion were the main driver for farmer's satisfaction from eco-friendly farming system. Therefore, when designing support policy, opportunity cost of conversion should be calculated by regional and local basis because the sustainability of agroenvironmental policy as well as the conservation of land and water resources is extremely important for both environment and human health. In the case of ÇATAK program, applications such as controlled use of pesticides and fertilizers has provided a basis for environmental protection. Significant changes were observed in almost all categories of applications after ÇATAK program. This shows that the reflection of ÇATAK program on the farmer practices is successful. It is expected that these farmers will make these practices a habit and continue in the following periods. It is important that this program has important consequences for the long-run viability. Consequently, similar policy programs like ÇATAK should reach more farmers in future.

\section{Acknowledgment}

This study is a part of the projectnumbered "TAGEM/ 14 / AR-GE / 64" and funding was provided by the Ministry of Agriculture and Forestry in 2016.

\section{References}

Bargali, S.S., M. Joshi and K. Bargali: Seasonal pattern of total soil respiration in age series of eucalypt plantation and mixed broadleaved forest in tarai belt of Kumaun Himalaya. Oecol. Mont., 2, 711 (1992).

Bargali, K., V. Manral, K. Padalia, S.S. Bargali and V.P. Upadhyay: Effect of vegetation type and season on microbial biomass carbon in Central Himalayan forest soils, India. Catena, 171, 125-135(2018).

Bargali, S.S., K. Padalia and K. Bargali: Effects of tree fostering on soil health and microbial biomass under different land use systems in central Himalaya. Land Degr. Develop., 30, 1984-1998 (2019). DOI: $10.1002 / / d r .3394$.

Boz, I.: Effects of environmentally friendly agricultural land protection programs: Evidence from the Lake Seyfe area of Turkey. J. Integra. Agricu., 15, 1903-1914 (2016). doi: 10.1016/S2095-3119(15) 61271-0

Boz, I.: Determinants of farmers' enrollment in voluntary environmental programs: Evidence from the Eregli Reed Bed area of Turkey. Environ. Develop. Sustain., 20, 2643-2661 (2018). https://doi.org/ 10.1007/s10668-017-0009-7.

Commission Regulation, (EC) 746/96 OJ L 102/19, Article 16 (1996).

Didarali, Z. and J. Gambiza: Permaculture: Challenges and benefits in improving rural livelihoods in South Africa and Zimbabwe. Sustainability,11, 2219 (2019). doi:10.3390/su11082219.

European Environment Agency: Integration of Environment into EU Agriculture Policy - The IRENA Indicator-Based Assessment Report, No 2/2006, ISSN 1725-9177(2006).

Gravetter, F.J. and L.B. Wallnau: Statistics For The Behavioral Sciences. $10^{\text {th }}$ Edn., ISBN:978-1-305-50491-2 (2015).

Höjgård, S. and E. Rabinowicz: Evidence-based agro-environmental policies: The Swedish experience, Evaluation of AgriEnvironmental Policies: Selected Methodological Issues and Case Studies- Chapter 3, pp. 71-89, OECD Publishing (2012). http://dx.doi.org/10.1787/9789264179332-en.

Huh, J.: An empirical assessment of environment-friendly agricultural program. Kor. Rur. Econ. Rev., 23, 17-36 (2000).

Joshi, M., K. Bargali and S.S. Bargali: Changes in physico- chemical properties and metabolic activity of soil in popular plantations replacing natural broad leaved forests. J. Arid Environ., 35, 161169 (1997).

Kim, C.G., S.I. Oh and T.Y. Kim: Evaluation and development directions of environmentally friendly agricultural policies (in Korean). Research Report C2003-4. Korea Rural Economic Institute (2003).

Mauchline, A.L., S.R. Mortimer, J.R. Park, J.A. Finn, K.Haysom, D.B. Westbury, G. Purvis, G. Louwagie, G. Northey, J. Primdahl, H.V ejre, L.S. Kristensen, K.V. Teilmann, J.P. Vesterager, K. Knickel, N. Kasperczyk, K. Balazs, L. Podmaniczky, G. Vlahos, S. Christopoulos, L. Kröger, J. Aakkula and A. Yli-Viikari: Environmental evaluation of agro-environment schemes using participatory approaches: Experiences of testing the AgroEnvironmental Footprint Index. Land Use Policy, 29, 317- 328 (2012).

Newbold, P.: Statistics For Business and Economics. $4^{\text {th }}$ Edn., New Jersey: Prentice Hall (1995).

Oladele, I. and L. Ward: Effect of micro-agricultural financial Institutions of South Africa Financial Services on Livelihood Capital of Beneficiaries in North West Province South Africa. Agricul. Food Secu., 6, 45 (2017).doi 10.1186/s40066-017-0122-8. 
Olhan, E., Y. Ataseven, S. Gün and H. Arısoy: The features of farmers preferring environmentally friendly agricultural methods: The case of Turkey. Sci. Res. Essa., 5, pp. 646-653, ISSN 1992-2248 (2010).

Öz, G. and İ. Boz: Adoption and diffusion of environment friendly agricultural land protection program in Kovada Canal Region of Eğirdir District of Isparta, XI.National Agricultural Economics Congress (Ulusal Tarım Ekonomisi Kongresi) Samsun, pp.15991605 (2014).

Pandey, C.B., D.K. Sharma and S.S. Bargali: Decomposition and nitrogen release from Leucaena leucociphala in Central India. Trop. Ecol., 47, 149-151 (2006).

Parihaar, R.S., K. Bargali and S.S. Bargali: Diversity and uses of ethnomedicinal plants associated with traditional agroforestry systems in Kumaun Himalaya. Ind. J. Agric. Sci., 84, 1470-1476 (2014).
Rathiya, P.S., R. Lakpale, G.K. Shrivastava and S.S. Bargali: Effect of nutrient blending with FYM on biomass production and economics under hybrid cotton-soybean intercropping system. J. Plant Develop. Sci., 2, 9-18 (2010).

Republic of Turkey, Official Gazette 31 March 2016 - Number: 29670 , Notification Number:2016/9 (2016).

Verma, P. and R. Sagar: Responses of diversity, productivity, and stability to the nitrogen input in a Tropical grassland. Ecological Applications, e02037 (In Press) (2019).

Yildirim, Ç., V. Ceyhan, E. Atış, H. Türkten, M. Hasdemir, H.E. Salalı, Y.Akyüz and F.Gungor: The effects of participating environmentally friendly agricultural land protection program on the farm level production efficiency in Samsun Province of Turkey. Custose @gronegócio on line-Vol. 14, 1808-2882 (2018). 